\title{
Parasite-Parasite Interactions in the Wild: How To Detect Them?
}

\author{
Eléonore Hellard, ${ }^{1,2, *}$ David Fouchet, ${ }^{1,3}$ Fabrice Vavre, ${ }^{1,3}$ and \\ Dominique Pontier ${ }^{1,3}$
}

Inter-specific interactions between parasites impact on parasite intra-host dynamics, host health, and disease management. Identifying and understanding interaction mechanisms in the wild is crucial for wildlife disease management. It is however complex because several scales are interlaced. Parasiteparasite interactions are likely to occur via mechanisms at the within-host level, but also at upper levels (host population and community). Furthermore, interactions occurring at one level of organization spread to upper levels through cascade effects. Even if cascade effects are important confounding factors, we argue that we can also benefit from them because upper scales often provide a way to survey a wider range of parasites at lower cost. New protocols and theoretical studies (especially across scales) are necessary to take advantage of this opportunity.

Parasite-Parasite Interactions: From The Lab to the Field

Parasites (see Glossary) are ubiquitous in the living world. Largely considered as agents of disease and death, parasites are now recognized as integral parts of ecosystems $[1,2]$ and as major driving forces for biological evolution [3,4].

However, research into host-parasite interactions remains dominated by the study of 'one hostone parasite' systems. Such studies ignore three important aspects that are emerging questions [2]. First, many potentially pathogenic agents silently circulate within host populations (e.g., [5]). Second, many parasites infect several host species (e.g., generalist parasites), with consequences for disease epidemiology and the selective pressures acting on each parasite and host [6]. Third, hosts can simultaneously carry several agents, with consequences for the dynamics of each parasite and for host health (e.g., $[7,8])$. In addition, understanding the spatiotemporal dynamics of diseases and the evolution of hosts and parasites requires integrating processes at different scales of ecological organization, space, and time from the within-host level (e.g., interactions of parasites with the host immune system, host resources, and coinfecting parasites) to the ecosystem or landscape level (e.g., influence of environmental variables and of host community composition on parasite dynamics); it implies moving from 'one host-one parasite' systems towards an ecosystem view of host-parasite interactions, embracing the real complexity of natural systems, one of the most exciting and challenging tasks for disease ecologists today $[2,9-11]$.

In this paper we focus on interactions between different species of parasites in wild hosts. Within a host, these parasites can interact with each other, modifying the intra-host and/or inter-host dynamics (spatial and/or temporal) of each other. Such parasite-parasite interactions increase
Trends

Hosts are often infected by more than one parasite species. Numerous experimental and clinical studies carried out at the host individual level have revealed that interactions between parasite species impact on parasite dynamics, host health, and disease management.

Field studies are still in their infancy and robust methods to detect parasiteparasite interactions in complex natural systems are lacking

In the wild, parasite-parasite interactions can occur not only through processes at the host individual level but also at population and community levels, stressing the need to investigate interaction mechanisms at various ecological scales.

Interactions occurring at one level can cascade up, translating into the epidemiological patterns observed at higher levels of organization.

We propose to use cascade effects to detect parasite-parasite interactions in the wild.

${ }^{1}$ Laboratoire de Biométrie et Biologie Evolutive, Université de Lyon, Université Lyon I, Centre National de la Recherche Scientifique (CNRS) Unité Mixte de Recherche 5558, 43 Boulevard du 11 Novembre 1918, 69622, Villeurbanne, France ${ }^{2}$ Percy FitzPatrick Institute, DST-NRF Centre of Excellence, University of Cape Town, Private Bag X3, Rondebosch 7701, South Africa 
(synergy) or decrease (antagonism) the susceptibility of the host to other agents, the inter-host transmission rate of the interacting parasites, and/or the severity of the disease symptoms they induce. They may also greatly influence the evolution of the parasites themselves, in particular the evolution of their virulence (reviewed in [12]). Many examples of parasite-parasite interactions have been identified, and there is now strong evidence of their impact on host health, parasite circulation, and pathogen management $[8,13-17]$. Despite this, few studies have looked at parasite interactions in wild populations (e.g., [15]). Considering the impact they can have on wildlife populations [18], that over $60 \%$ of human diseases may have a zoonotic origin [19,20], and that a substantially higher percentage of livestock diseases are probably shared with other wild-ranging hosts [21], more work on parasite-parasite interactions in wild populations is needed. Their better detection and understanding are crucial to prevent and manage infectious diseases. The identification of synergies between different parasite species may help to prevent population declines or extinctions. By contrast, where interactions are antagonistic, measures targeting only one parasite species may result in unexpected increases in a second cocirculating parasite species [22,23]. Recent studies suggest that antagonist parasites may also help in fighting problematic pathogens in natural populations, as exemplified by the protective effect of Janthinobacterium lividum against chytridiomycosis in amphibians [24] and of diverse microbial enemies of nematodes in dune plants [25].

Current knowledge of parasite-parasite interactions largely results from animal models and from experimental and clinical studies with an individual-based approach. These studies are biased towards human pathogens and suspected interactions (e.g., following the observation of increased mortality in a population). They also focus on mechanisms occurring at the withinhost level (e.g., mediated by the host immune system, Table 1), whereas, as will be developed further, interactions between parasites can also occur via mechanisms occurring at the host population [26] and probably higher levels of organization. Interaction mechanisms resulting in particular from host behavior have been largely ignored, despite its crucial role in transmission processes [27]. A mechanistic approach, aiming at deciphering the underlying processes of parasite-parasite interactions, is necessary to go beyond the simple description of parasite associations patterns. Community ecology already proved to be useful to understand processes shaping within-host parasite communities (e.g., top-down and bottom-up regulation of parasite population size, via host immune system and resources, respectively) $[9,11,28]$, but so far no framework includes higher scales.

Studies are now beginning to be extended to natural populations (e.g., [15]), but detecting and identifying parasite-parasite interactions and their underlying mechanisms represent a methodological challenge in complex food webs [29]. The difficulty resides in the existence of multiple confounding factors (e.g., parasites transmitted by a similar vector or a similar behavior, and environmental factors exposing hosts to several parasites simultaneously) and possible mismatches between the level of organization under study and the level of organization at which the interaction occurs. Long-term field studies are rare and costly and an increasing effort is also put on developing methods to deal with more usual empirical epidemiological data such as presence/absence data obtained in cross-sectional studies, that is, sampling multiple host individuals, populations, or communities at one time [29,30]. Other questions have been poorly investigated and represent interesting avenues of research. Are there traces of within-host interactions at higher levels of organization (i.e., do parasite-parasite interactions cascade up?). In other words, can we detect parasite-parasite interactions by examining patterns at levels higher than the level of their underlying mechanism? What types of patterns can be expected? or, put differently - what are the consequences of within-host interactions for the spatiotemporal dynamics of interacting parasites within host populations, communities, or at the regional scale? Being able to interpret epidemiological patterns obtained in the field at different scales, and to link the observed patterns to different types of parasite-parasite interactions and their mechanisms,
${ }^{3}$ LabEx Ecofect, Ecoevolutionary Dynamics of Infectious Diseases, University of Lyon, France

${ }^{*}$ Correspondence: eleonore.hellard@gmail.com (E. Hellard). 
Table 1. Mechanisms of Direct Parasite-Parasite Interactions at the Within-Host Level

\begin{tabular}{|c|c|c|c|c|c|}
\hline $\begin{array}{l}\text { Function } \\
\text { Affected }\end{array}$ & $\begin{array}{l}\text { Interaction } \\
\text { Type }^{a}\end{array}$ & Mechanism & Details & Examples & Refs \\
\hline \multirow[t]{2}{*}{ Cell entry } & \multirow[t]{2}{*}{ Positive } & \multirow[t]{2}{*}{$\begin{array}{l}\text { Mechanical } \\
\text { facilitation }\end{array}$} & \multirow[t]{2}{*}{$\begin{array}{l}\text { Creation of an entry point } \\
\text { for other parasites }\end{array}$} & $\begin{array}{l}\text { Herpes simplex virus } \\
\text { type } 2-H I V \text { in humans }\end{array}$ & [69] \\
\hline & & & & $\begin{array}{l}\text { Argulus coregoni- } \\
\text { Flavobacterium } \\
\text { columnare in fish }\end{array}$ & [70] \\
\hline \multirow[t]{2}{*}{ Survival } & Negative & Interference & $\begin{array}{l}\text { Parasites killing other } \\
\text { parasites }\end{array}$ & $\begin{array}{l}\text { Bacteria producing } \\
\text { bacteriocins (e.g., } \\
\text { Photorhabdus, } \\
\text { Xenorhabdus) }\end{array}$ & {$[71,72]$} \\
\hline & Positive & Cooperation & $\begin{array}{l}\text { Production of public } \\
\text { goods }\end{array}$ & $\begin{array}{l}\text { Bacteria, yeast, and } \\
\text { fungi producing } \\
\text { siderophores (iron-binding } \\
\text { molecules) }\end{array}$ & [73] \\
\hline Fecundity & $\begin{array}{l}\text { Positive or } \\
\text { negative }\end{array}$ & Competition & $\begin{array}{l}\text { Change of life-history } \\
\text { strategy when there } \\
\text { is conflict over } \\
\text { transmission }\end{array}$ & $\begin{array}{l}\text { Increased egg production } \\
\text { of Coitocaecum parvum } \\
\text { (whose definitive host is a fish) } \\
\text { before Microphallus sp. } \\
\text { (whose definitive host is a bird) } \\
\text { succeeds in manipulating } \\
\text { their shared intermediate host }\end{array}$ & [74] \\
\hline \multirow[t]{2}{*}{$\begin{array}{l}\text { Genome } \\
\text { expression }\end{array}$} & \multirow[t]{2}{*}{$\begin{array}{l}\text { Positive or } \\
\text { negative }\end{array}$} & Transactivation & $\begin{array}{l}\text { The gene products of } \\
\text { a parasite induce } \\
\text { transactivation of the } \\
\text { genes of another parasite }\end{array}$ & Herpes simplex virus-HIV-1 & [69] \\
\hline & & $\begin{array}{l}\text { Embedded } \\
\text { parasites }\end{array}$ & $\begin{array}{l}\text { Integration of exogenous } \\
\text { genetic material from a } \\
\text { parasite modifies the } \\
\text { pathogenicity of another } \\
\text { parasite }\end{array}$ & CTX phi within Vibrio cholerae. & [75] \\
\hline
\end{tabular}

${ }^{\text {a }}$ From the point of view of the parasite.

will help in identifying the processes and the ecological and co-evolutionary consequences of parasite-parasite interactions from the molecule to the ecosystem.

Current knowledge does not permit all these questions to be answered, and in the following we review what is known so far on the existence and mechanisms of parasite-parasite interactions in the wild and discuss cascade effects of parasite-parasite interactions and their potential use to detect parasite-parasite interactions in natural populations. Where possible, concrete examples highlighting the different mechanisms are given, but some other mechanisms, theoretical and not yet demonstrated, are also presented.

\section{Parasite-Parasite Interactions: A Ubiquitous Phenomenon in the Wild?}

Macro-parasites are the most studied in the wild. Interactions between intestinal helminths have been evidenced in diverse mammals (e.g., [13,31]), birds [32], fish [33], and invertebrates [34], with emphasis on parasite localization (e.g., [35]), abundance (e.g., [36]), life-history strategies, body size, and fecundity ([37] and references therein) within the host. Nonetheless, many observational approaches used until recently generated inconsistent results on the importance of such interactions in structuring macro-parasite communities [13,38-40]. Detecting parasiteparasite interactions from abundance data is not easy, and such inconsistencies might have been due to the absence of robust validated methods of detection until recently [29]. The nature and consequences of interactions between macro-parasites in wild populations thus remain to be better estimated.

\section{Glossary}

Antigenically-similar parasites:

with similar antigens, therefore recognized by the same host antibodies and immune cells.

Cascade effect: (in the context of parasite interactions) the spread of a parasite interaction to upper levels of organization, impacting the spatiotemporal dynamics of the interacting parasites at levels at which interaction does not initially occur. For instance, an interaction occurring within hosts will impact on the withinhost dynamics of the interacting parasites as well as on their dynamics at the host population and community levels.

False parasite interaction:

statistical association of two or more parasites resulting from shared risk factor(s). When the same host individuals or populations are at risk of infection by both parasites, these parasites are likely to be found together in the same hosts or populations even if parasites do not interact biologically (i.e., even if there is no true interaction). These frequent associations may provide an ideal context for coevolution between parasites to take place.

\section{Horizontally transmitted parasite:} transmitted through direct or indirect contact with infected individuals, in contrast to vertically transmitted parasites that spread from one generation to another (i.e., from mother to fetus or newborn).

Next-generation sequencing: highthroughput genome sequencing that parallelizes the sequencing process, producing thousands or millions of sequences concurrently.

Parasite: any organism living at the expense of another, in other words any micro- (e.g., virus, bacterium, protozoon, fungus) or macro- (e.g., helminth, arthropod) parasite. Serotypes: microorganisms belonging to the same species and sharing the same antigenic profile, and are hence recognized by the same specific host antibodies.

Susceptibility: relative likelihood that a host becomes infected and mounts a sub-threshold immune response when exposed to an infectious dose at a given time. In most cases the capacity of a parasite to establish an infection depends on the initial state of the immune system of the exposed host, which is determined by previous and current infections as 
More recently, interactions between micro-parasites, as well as between micro- and macroparasites, were also revealed in the wild. We can cite (i) the antagonism between bovine tuberculosis and worms that was shown to accelerate host mortality and have immunedriven effects on the susceptibility of free-ranging African buffalos (Syncerus caffer) [41], and (ii) the modification of field vole (Microtus agrestis) susceptibility due to the interactions between the cowpox virus, Babesia microti, Bartonella spp., and Anaplasma phagocytophilum [15]. Consequences can be dramatic. In honeybees, the mite Varroa destructor can destabilize the within-host dynamics of the deformed wing virus, transforming a cryptic virus into a rapidly-replicating killer and participating in the collapse of honeybee colonies (Apis mellifera L.) [18].

Parasite-parasite interactions thus appear to occur in many types of hosts and between multiple types of parasites. However, their importance in structuring parasite and host communities as well as their underlying mechanisms in wild populations need to be better investigated.

\section{Parasite-Parasite Interactions at the Ecological Level}

Interactions between parasites, as those between free living species, can be viewed as an ecological problem in which the different actors interact with each other.

Within host individuals, the spread of a parasite is the result of interactions between the parasite community, the host immune system, and parasite resources (Figure $1 \mathrm{~A}$ ). The different parasite species can compete with each other either directly (interference competition, Table 1) or indirectly (apparent or exploitation competition, Table 2) (reviewed in [7]).

At the host population level, parasites need to spread to new hosts. Three steps are necessary: exit from the host, at-risk contact, and successful invasion of the new host (Figure 1B). If one parasite alters any of these steps for another parasite, there is a potential interaction. Exit from the host can be facilitated by infection symptoms (e.g., rashes, cough), which can increase the transmission of other parasites with the same transmission mode. The shedding rate of a parasite can also be modified in presence of another parasite, as for Heligmosomoides polygyrus in presence of Bordetella bronchiseptica, resulting in some super-shedder hosts [42]. Atrisk contacts are, in a larger extent, conditioned by host behavior, which can be affected by parasites. For example, rabies causes aggressiveness and wandering in red foxes (Vulpes vulpes) [43], increasing the spread of the virus and of other parasites transmitted by bites. A parasite can also affect the spread of other parasites by inducing mass mortality and/or individual convalescence, hence reducing the pool of susceptible hosts ('ecological interference' [26]) and preventing simultaneous outbreaks of other parasites. First evidenced between serotypes of dengue viruses, between strains of echoviruses, and between measles and whooping cough [26], it also occurs between the rabbit hemorrhagic disease virus (RHDV) and the myxoma virus in European rabbits (Oryctolagus cuniculus) [44]. An epidemic of RHDV can kill up to $90 \%$ of the infected individuals, compromising the transmission of the myxoma virus and delaying its annual epidemic [44]. During the third step, the invasion of a new host by a parasite can be affected by the presence of other parasites. For example, the immune memory acquired from a different parasite can reduce the susceptibility of the host to other infections (i.e., cross-immunity). This mechanism has been proposed to explain why European wild rabbits are less susceptible to the helminth Graphidium strigosum after infection by Trichostrongylus retortaeforms [13]. Note that the phenomenon of crossimmunity has consequences for both within- (causing less-severe infection) and betweenhost (reducing host susceptibility) dynamics.

At the host meta-population or host community level, some parasites require spreading to other subpopulations of the same host species and/or of different host species to maintain or achieve well as by intrinsic factors such as the age, sex, nutritional status, and genotype of the host.

True parasite interaction: biological interaction between two or more parasites. There is a parasite interaction when one parasite increases (synergy) or decreases (antagonism) the infection risk disease severity, and/or transmission rate of the other agent(s). Interactions can be unidirectional (parasite $A$ influences parasite B) or bidirectional (reciprocal influences of $A$ on $B$ and of $B$ on $A$ ), direct (e.g., interference competition), or indirect (e.g., via the host immune system), and occur within host individuals, populations, or communities.

Type 1 T helper cell (Th1): a type of $\mathrm{T}$ lymphocyte triggered by cytokines interleukin (IL) IL-12 and IL2 after the detection of an intracellular antigen (usually a micro-parasite) that induces a cellular immune response (i.e., via cytotoxic T cells and natural killer cells).

Type 2 T helper cell (Th2): a type of $\mathrm{T}$ lymphocyte triggered by cytokine IL-4 after the detection of an extracellular antigen (usually a macroparasite) that induces a humoral immune response (i.e., via specific antibodies). 
(A) Within-host scale
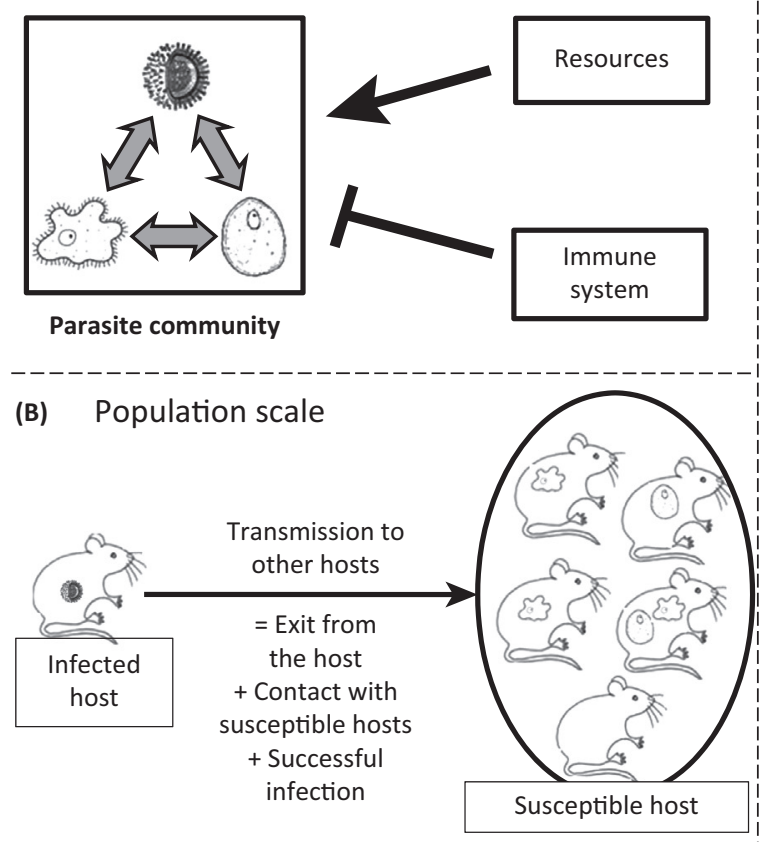

(c) Upper scales

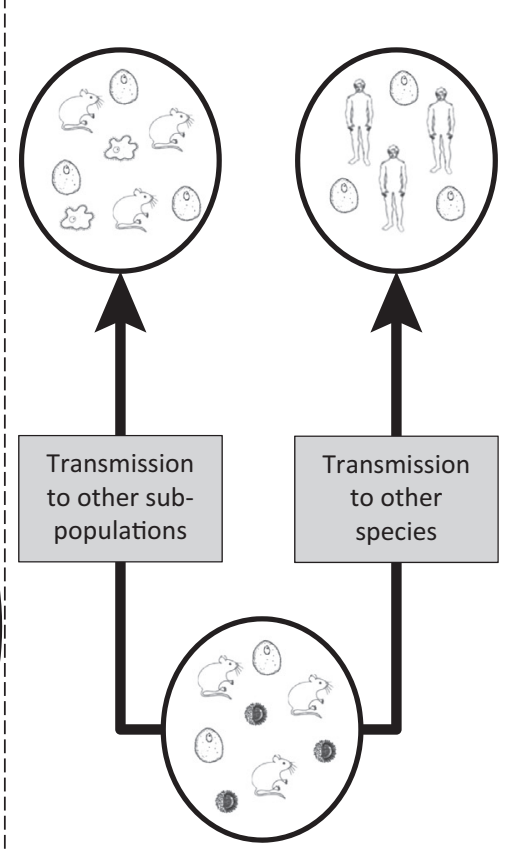

Trends in Parasitology

Figure 1. Parasite-Parasite Interactions May Occur at Different Levels of Organization. (A) At the within-host level, parasites may interact either directly (by affecting each other's survival and/or replication rates) or indirectly through resource competition or through the host immune response. (B) At the host population level, parasite transmission results from three successive steps [exit from the host, at-risk encounter with susceptible hosts, and parasite entry within new host (s)] during which the presence of other parasites may play an important role. (C) At the host meta-population or community level, the presence of multiple parasites may affect the probability of successful transmission of a given parasite to different sub-populations of the same host species (e.g., through behavioral manipulation affecting dispersal) or to different host species.

their life cycle. In that case, host behaviors such as dispersal (for intra-species transmission to other subpopulations) or escape from predators (for between-species transmission) are fundamental factors that can be affected by other parasites. For instance, host dispersal is probably severely reduced by pathogens inducing high fever. Regarding inter-specific transmission, one parasite may manipulate the behavior of its intermediate host in a way that favors its trophic transmission, impacting simultaneously on the transmission of other parasites (reviewed in [45]). For example, the larvae of three species of helminth were shown to manipulate the behavior of their common intermediate host, a crab, in a way that increases their transmission to their definitive host, a shorebird [46]. It is worth noting that such an interaction at the host community level can also create a 'false' (i.e., statistical) interaction at the definitive host level. Parasites that are transmitted together will be positively associated within host individuals even if they do not interact in their definitive host [47].

To conclude, parasite-parasite interactions can occur at different levels of organization through different mechanisms. Interactions at the intra-host level have been much more extensively documented than those at the upper levels. However, the latter should not be neglected because (i) they can be fundamental factors to understand the spread and impact of important pathogens, and (ii) they can produce parasite associations at upper levels that are important to disentangle from intra-host interaction mechanisms. 
Table 2. Mechanisms of Indirect Parasite-Parasite Interactions at the Within-Host Level

\begin{tabular}{|c|c|c|c|c|c|}
\hline $\begin{array}{l}\text { Interaction } \\
\text { Through }\end{array}$ & Effect $^{a}$ & Mechanism & Details & Examples & Refs \\
\hline \multirow[t]{5}{*}{$\begin{array}{l}\text { Immune } \\
\text { system }\end{array}$} & \multirow[t]{2}{*}{ Positive } & \multirow[t]{2}{*}{ Immunosuppression } & \multirow{2}{*}{$\begin{array}{l}\text { A parasite reduces the } \\
\text { efficacy of the immune } \\
\text { system }\end{array}$} & $\begin{array}{l}\text { HIV-1-opportunistic } \\
\text { infections, HIV-1-malaria }\end{array}$ & [8] \\
\hline & & & & $\begin{array}{l}\text { Varroa destructor-deformed } \\
\text { wing virus in honeybees }\end{array}$ & [18] \\
\hline & \multirow[t]{2}{*}{$\begin{array}{l}\text { Positive or } \\
\text { negative }\end{array}$} & $\begin{array}{l}\text { Alteration of immune } \\
\text { cell activation }\end{array}$ & $\begin{array}{l}\text { A parasite alters the } \\
\text { activation state of } \\
\text { potential host cells or } \\
\text { immune cells }\end{array}$ & $\begin{array}{l}\text { HIV-human cytomegalovirus } \\
\text { (lymphocyte activation) }\end{array}$ & [76] \\
\hline & & Th1/Th2 trade-off & $\begin{array}{l}\text { The induction by a } \\
\text { parasite of a Th1 (or Th2) } \\
\text { response in its host } \\
\text { reduces host ability to } \\
\text { fight against a parasite } \\
\text { inducing a Th2 (or Th1) } \\
\text { response }\end{array}$ & $\begin{array}{l}\text { Helminths (Th2)- } \\
\text { Plasmodium (Th1) }\end{array}$ & [77] \\
\hline & Negative & Cross-immunity & $\begin{array}{l}\text { Host immunity to one } \\
\text { parasite is effective } \\
\text { against an } \\
\text { antigenically-similar } \\
\text { but different parasite }\end{array}$ & $\begin{array}{l}\text { Trichostrongylus } \\
\text { retortaeforms-Graphidium } \\
\text { strigosum in wild rabbits }\end{array}$ & [13] \\
\hline \multirow[t]{4}{*}{ Resources } & \multirow[t]{3}{*}{ Negative } & \multirow[t]{3}{*}{ Competition } & \multirow{3}{*}{$\begin{array}{l}\text { Indirect competition } \\
\text { between parasites using } \\
\text { the same limiting } \\
\text { resource }\end{array}$} & $\begin{array}{l}\text { Niche-shifting of } \\
\text { gastrointestinal helminths } \\
\text { in wild rabbits }\end{array}$ & [13] \\
\hline & & & & $\begin{array}{l}\text { Micro-parasites infecting } \\
\text { red blood cells-helminths } \\
\text { causing anemia }\end{array}$ & [28] \\
\hline & & & & $\begin{array}{l}\text { Reduction in body size } \\
\text { and egg production of } \\
\text { gastrointestinal helminths }\end{array}$ & [74] \\
\hline & $\begin{array}{l}\text { Positive or } \\
\text { negative }\end{array}$ & $\begin{array}{l}\text { Alteration of } \\
\text { receptor expression }\end{array}$ & $\begin{array}{l}\text { A parasite alters the } \\
\text { expression of host } \\
\text { receptors for another } \\
\text { parasite }\end{array}$ & $\begin{array}{l}\text { Human herpes virus } 6 \\
\text { induces the expression of } \\
C D 4 \text { receptors, the receptors } \\
\text { for HIV-1, on the surface of } \\
T \text { cells }\end{array}$ & [78] \\
\hline
\end{tabular}

${ }^{\mathrm{a} O n}$ one or both parasite(s).

\section{Using Cascade Effects to Detect Parasite-Parasite Interactions in the Wild?}

Beyond the need to further investigate the mechanisms of parasite-parasite interactions in natural systems, and in particular at less-investigated scales, little is known on how interactions translate across other levels of organization and impact on the spatiotemporal dynamics of the parasites at levels at which their interaction does not initially occur. These cascade effects might be of particular interest to detect parasite-parasite interactions in the wild, and are discussed below.

\section{Evidence of Cascade Effects in the Wild}

In theory, as soon as a parasite-parasite interaction alters the transmission rate of one or both parasite(s) to other host individuals, species, or subpopulations (i.e., to one level higher than that at which the parasites interact), it should cascade to the upper levels of organization and translate into specific epidemiological patterns and spatiotemporal dynamics for each parasite. The strength of the association patterns between the parasites may, however, be diluted as it proceeds from one level the next; its strength should depend in part on initial strength of the interaction. Within-host antagonisms due to phenomena such as cross-immunity and 
immunological trade-offs were shown to lead to separate geographical distributions or asynchronous epidemics at the population, meta-population, and/or upper levels. Jolles et al. [41] showed, for instance, that immunological trade-offs, together with accelerated mortality of coinfected African buffalos, led to negative associations of tuberculosis and intestinal worms across different scales: within herds, among herds, and at the whole-population level. Cascade effects of parasite-parasite interactions can also translate into modifications of the temporal dynamics of the interacting parasites. Cross-immunity phenomena between two gut helminths of the wild rabbit (Oryctolagus cuniculus) were shown to induce a shift in the seasonal abundance of the two parasites in the rabbit population, forcing them to be out of phase [48].

By contrast, synergisms may create overlapping distributions and/or synchronous epidemics [49]. Positive cascading between the within-host and the host population levels will occur as soon as a parasite-parasite interaction increases the acquisition and/or transmission of the interacting parasites. Coinfection by the respiratory bacteria Bordetella bronchiseptica and the gastrointestinal helminth Heligmosomoides polygyrus turns for instance mice into helminth super-shedders [42].

In addition, changes in the spatiotemporal dynamics of parasites other than the targeted species following big campaigns of vaccination or treatment could be indicative of parasite-parasite interactions because such interventions can reveal the presence of other pathogens that were attenuated before $[23,50,51]$. This suggests that parasite-parasite interactions might also cascade down, and this would deserve more attention.

\section{On the Need for Methodological Tools}

Several studies therefore suggest that parasite-parasite interactions do cascade up across levels of organization. The patterns of association observed at each level are likely to depend on the underlying mechanisms of the parasite-parasite interaction and on its impact on host demography, highlighting the importance of adopting a mechanistic approach. In addition, processes at the within-host level may not always be visible at the population or community level, or, conversely, association patterns may not result from parasite-parasite interactions but may be due to other, confounding, factors. Risk factors shared by two or more parasites (i.e., factors increasing the probability of infection by both/all parasites) can, for instance, create false interactions, in other words statistical associations between parasites that do not interact biologically (Box 1). False interactions can occur at the level of the host individual (e.g., confounding effects of host age, sex), population (e.g., confounding effects of host sex-ratio, age-structure, density), or landscape (e.g., confounding effects of geological and climatic factors). The latter can influence the structure of parasite communities, as shown in the Puumala virus-helminth-bank vole (Myodes glareolus) system [52]. Although both parasites were present in the entire study area, their association in bank voles was only observed in the northern part of the region that is distinct from the South in terms of climate and primary soils. These factors, that affect both the development and survival of helminth transmission stages and Puumala virus prevalence, created false associations between the parasites at the scale of the study site [52]. Climatic events can also synchronize some epidemics that are usually out of phase [53]. Using cascade effect to detect parasite-parasite interactions therefore requires appropriate study designs, measures, and statistical methods (Table 3, Figure 2) [54].

New methodological tools are being developed to distinguish parasite association patterns due to parasite-parasite interactions from those due to confounding factors at a given scale (Box 1). New modeling tools are also being developed to interpret patterns across scales, although they are for now limited to systems in which the epidemiological and demographic processes are well understood $[54,55]$. Other tools such as structural equation models [56], which are less used in disease ecology but that have proved to be useful in the study of trophic cascades (and their 


\section{Box 1. In the Field: Dealing With Confounding Factors}

In natural populations, the study of micro-parasites is often cross-sectional and based on indirect signs such as specific antibodies - in other words, presence/absence data. In contrast to macro-parasites, whose follow-up can be quantitative (fecal or blood counts), micro-parasite infections are often short and shedding times too brief to make the search for the micro-parasites themselves efficient. This would require capturing hosts exactly when they are infectious. Most field data are thus limited to observed frequencies of seronegative and single- or double-seropositive individuals, with no information on the time or intensity of infection.

In this context, searching for interactions consists of determining whether parasites are more often associated than would be expected by chance. A classical method to test for this hypothesis is the Pearson chi-square $\left(\chi^{2}\right)$ test. It compares the observed frequencies to those expected if parasites are truly independent, under the null hypothesis that the joint distribution of the cell counts in a contingency table is the product of the row and column marginals. However, such a method ignores confounding factors, and significant associations detected in this manner can be biological (true) or statistical (false) interactions. For instance, if males are more at risk for parasites $A$ and $B$, these may appear associated even if they do not interact (Figure I).

\section{Pearson's $\chi^{2}$ per gender}

(only observed frequencies are shown)

\begin{tabular}{|c|c|c|}
\hline C1 & A- & A+ \\
\hline B- & 4 & 16 \\
\hline B+ & 16 & 64 \\
\hline
\end{tabular}

$\chi^{2}=0$

\begin{tabular}{|c|c|c|}
\hline Y & A- & A+ \\
\hline B- & 64 & 16 \\
\hline B+ & 16 & 4 \\
\hline \multicolumn{3}{c}{$\chi^{2}=0$} \\
\hline
\end{tabular}

Pearson's $\chi^{2}$ on the whole population (only observed frequencies are shown)

\begin{tabular}{|c|c|c|}
\hline \multicolumn{1}{|c|}{ A- } & A+ \\
\hline B- & 68 & 32 \\
\hline B+ & 32 & 68 \\
\hline \multicolumn{3}{|c|}{$\chi^{2}=25.92$} \\
\hline
\end{tabular}

Trends in Parasitology

Figure I. Parasites A and B are Statistically Independent Within Genders (left). Conversely, there is a false interaction between them if one does not distinguish between genders (right). Alternative methods allow the expected frequencies to be determined in a modified $\chi^{2}$ analysis that accounts for confounding factors. Some are based on the estimation of 'pre-interactive' species prevalence [79], and require previous knowledge of dominance relationships between parasites. Others use log-linear models (e.g., [80]) or logistic regression analysis (e.g., [41]). However, these latter methods are based on an asymptotic approximation of the deviance, which might not be relevant for small samples. When the sample size is small relative to the number of model parameters, one can use the corrected $\chi^{2}$ [30] which estimates expected frequencies using logistic regressions and was shown to be more robust. This method enables correction for confounding factors existing at any organization level (e.g., at the individual level, at the landscape level).

effects on disease [57]), should allow multiple causal models to be compared rigorously and concurrently using empirical experimental and field data.

\section{Studies at What Scale(s)? Trade-Offs Between Ease of Data Collection and Data Analysis}

Field studies are necessarily carried out on only a limited range of scales. The scales of observation may be chosen deliberately to elucidate key features of the natural system, but are often imposed on us by our perceptual limitations or by technological or logistical constraints. Each scale presents advantages and disadvantages, and trade-offs must be made between the ease of data acquisition and the purpose of the study. Studies at lower levels, such as experimental coinfections, give access to molecular mechanisms. Field protocols surveying host coinfection status inform on coinfection probabilities and on symptoms (cross-sectional and longitudinal studies), as well as on their impact on survival and reproduction (longitudinal studies). These field measures are highly valuable because they can be drastically different from those taken in the lab. At upper levels, associations between parasites can be suspected, but deciphering the underlying mechanisms is almost impossible. 
Table 3. Different Study Designs to Answer Different Questions

\begin{tabular}{|c|c|c|c|c|c|}
\hline Study Design & Level(s) & Data Type & Aims & Limits & Refs \\
\hline \multicolumn{6}{|c|}{ Experimental (lab) } \\
\hline $\begin{array}{l}\text { Experimental } \\
\text { coinfection of } \\
\text { animal models } \\
\text { or cells }\end{array}$ & $\begin{array}{l}\text { Molecule, } \\
\text { cell, host }\end{array}$ & $\begin{array}{l}\text { Quantitative }^{a} \\
\text { Presence/absence }^{b} \\
\text { Clinical }^{c} \\
\text { Location of parasites } \\
\text { within host }\end{array}$ & $\begin{array}{l}\text { Identify underlying } \\
\text { mechanisms } \\
\text { Determine the } \\
\text { direction of the } \\
\text { interaction } \\
\text { Evaluate the influence } \\
\text { of the order of } \\
\text { infection } \\
\text { Search for co- } \\
\text { evolutionary patterns } \\
\text { between parasites } \\
\text { and between hosts } \\
\text { and parasites }\end{array}$ & $\begin{array}{l}\text { Requires suspicion of } \\
\text { interaction } \\
\text { Mainly applied to } \\
\text { infections impacting } \\
\text { on host health } \\
\text { Simplified unrealistic } \\
\text { system, ignores the } \\
\text { ecological context }\end{array}$ & [81] \\
\hline \multicolumn{6}{|c|}{ Case-control study (field) } \\
\hline $\begin{array}{l}\text { Comparison of } \\
\text { coinfected } \\
\text { hosts to a } \\
\text { control group }\end{array}$ & Host & $\begin{array}{l}\text { Quantitative }^{a} \\
\text { Presence/absence }^{b} \\
\text { Clinical }^{c} \\
\text { Location of parasites } \\
\text { within the host }\end{array}$ & $\begin{array}{l}\text { Assess the impact of } \\
\text { simultaneous } \\
\text { infections on survival } \\
\text { and disease severity }\end{array}$ & $\begin{array}{l}\text { No historical } \\
\text { information (time or } \\
\text { order of infection, } \\
\text { previous infections) } \\
\text { Control group } \\
\text { (susceptibles; singly } \\
\text { infected) hard to } \\
\text { generate }\end{array}$ & [82] \\
\hline \multicolumn{6}{|c|}{ Cross-sectional study (field) } \\
\hline $\begin{array}{l}\text { Hosts from one } \\
\text { or several } \\
\text { population(s) } \\
\text { are sampled } \\
\text { once at the } \\
\text { same time }\end{array}$ & $\begin{array}{l}\text { Host, } \\
\text { population, } \\
\text { community, } \\
\text { ecosystem }\end{array}$ & $\begin{array}{l}\text { One sample per host } \\
\text { Quantitative }^{\mathrm{a}} \\
\text { Presence/absence }^{\mathrm{b}} \\
\text { Clinical }^{\mathrm{C}} \\
\text { Location of parasites } \\
\text { within host }\end{array}$ & $\begin{array}{l}\text { Identify interactions } \\
\text { Estimate probability of } \\
\text { coinfection }\end{array}$ & $\begin{array}{l}\text { For common parasites } \\
\text { No historical } \\
\text { information (time or } \\
\text { order of infection, } \\
\text { previous infections) }\end{array}$ & [30] \\
\hline \multicolumn{6}{|c|}{ Longitudinal study (field) } \\
\hline $\begin{array}{l}\text { Hosts are } \\
\text { repeatedly } \\
\text { sampled over a } \\
\text { specified } \\
\text { period of time }\end{array}$ & $\begin{array}{l}\text { Host, } \\
\text { population, } \\
\text { community, } \\
\text { ecosystem }\end{array}$ & $\begin{array}{l}\text { Chronological data } \\
\text { Quantitative }^{\mathrm{a}} \\
\text { Presence/absence }^{\mathrm{b}} \\
\text { Clinical }^{\mathrm{C}} \\
\text { Location of parasites } \\
\text { within host }\end{array}$ & $\begin{array}{l}\text { Identify interactions } \\
\text { Estimate probability of } \\
\text { coinfection } \\
\text { Determine the } \\
\text { direction of the } \\
\text { interaction } \\
\text { Evaluate the influence } \\
\text { the order of infection } \\
\text { Evaluate the impact of } \\
\text { coinfections on host } \\
\text { fitness } \\
\text { Study cascade effects }\end{array}$ & $\begin{array}{l}\text { Harder to carry } \\
\text { Requires significant } \\
\text { efforts (costly, long in } \\
\text { duration) } \\
\text { Possible ethical } \\
\text { problems in natural } \\
\text { populations (frequent } \\
\text { captures or sampling) }\end{array}$ & [15] \\
\hline \multicolumn{6}{|c|}{ Interventions (including randomized controlled trials) (lab or field) } \\
\hline $\begin{array}{l}\text { Comparison of } \\
\text { hosts receiving } \\
\text { or not a } \\
\text { medical } \\
\text { intervention } \\
\text { (random } \\
\text { allocation). }\end{array}$ & $\begin{array}{l}\text { Host, } \\
\text { population, } \\
\text { community, } \\
\text { ecosystem }\end{array}$ & $\begin{array}{l}\text { Chronological or } \\
\text { paired data } \\
\text { Quantitative }^{a} \\
\text { Presence/absence }^{\mathrm{b}} \\
\text { Clinical }^{\mathrm{C}} \\
\text { Location of parasites } \\
\text { within host }\end{array}$ & $\begin{array}{l}\text { Evaluate the impact of } \\
\text { an intervention (e.g., } \\
\text { treatment) against a } \\
\text { coinfection (e.g., for } \\
\text { the host; for regional } \\
\text { prevalence) } \\
\text { Identify parasite- } \\
\text { parasite interactions } \\
\text { Study cascade effects }\end{array}$ & $\begin{array}{l}\text { Possible ethical } \\
\text { problems (some hosts } \\
\text { are not treated/ } \\
\text { vaccinated) }\end{array}$ & {$[22,51]$} \\
\hline
\end{tabular}

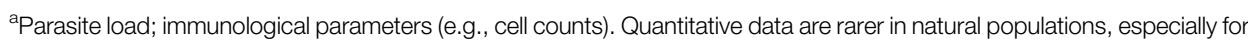
micro-parasites, but should become more frequent with the development of new diagnostic tools.

${ }^{\mathrm{b}}$ Specific antibodies.

'Symptoms (nature, evolution); duration of infection. 


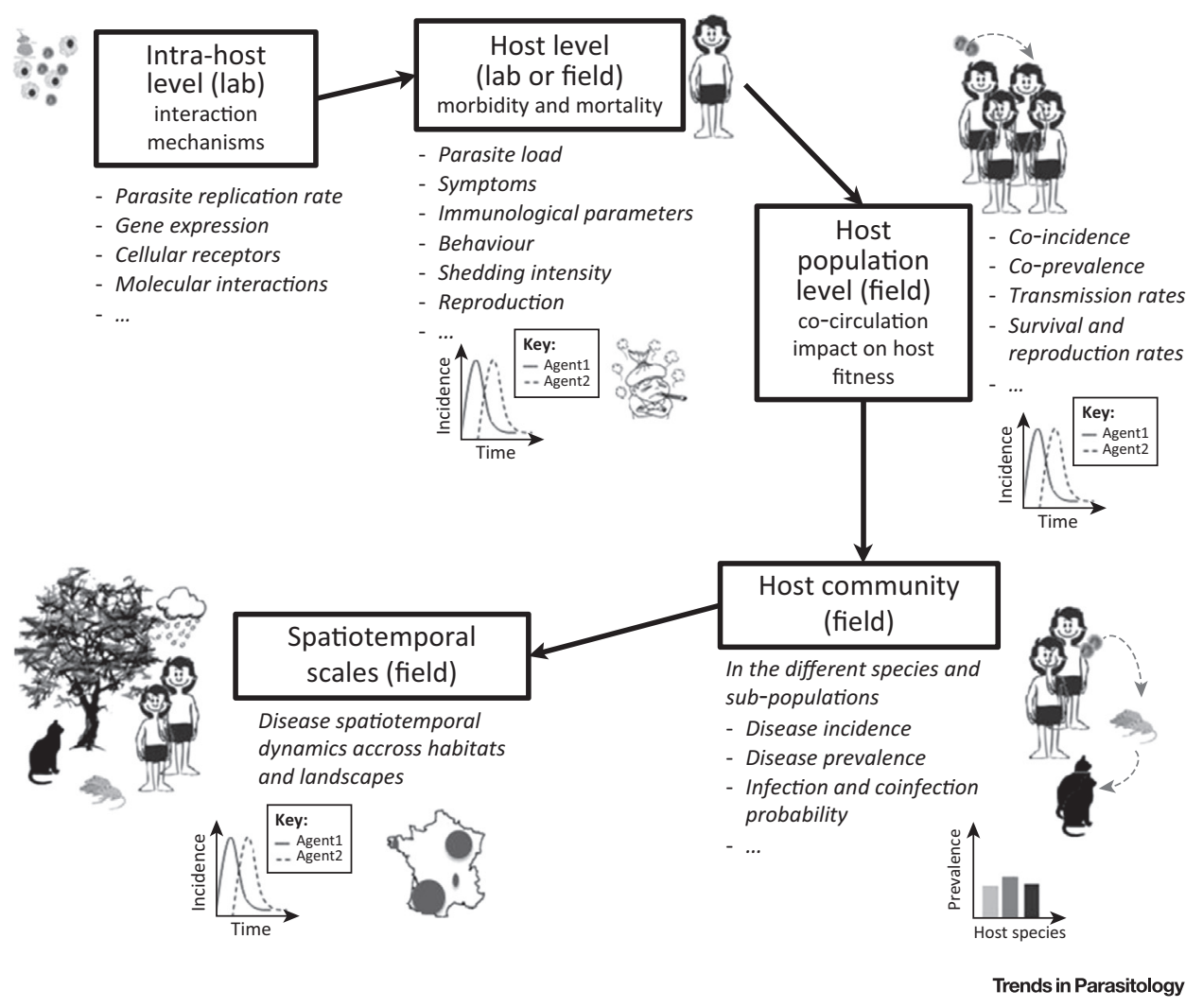

Figure 2. Detection of Parasite-Parasite Interactions: From the Molecular to the Ecosystem Level. Parasite interactions can be detected from intra-host levels (i.e., from molecules to organs) to the global level. An interaction occurring at a given level may spread to higher levels of organization, affecting the (spatiotemporal) dynamics of the interacting infectious agents at the upper levels. At each level, different specific measures can be made (italicized). Interpreting the observed patterns in terms of biological interactions is rendered difficult by the existence of several confounding factors whose number accumulates as the interaction cascades to the upper levels of organization.

Nevertheless, upper levels of organization are very important because empirical data acquisition tends to be easier at higher levels in the field. The search for parasite-parasite interactions in the lab is very costly and requires knowing what to look at and where, whereas comparing the geographic distribution of two animal pathogens can be achieved using existing epidemiological data. Field protocols monitoring host coinfection status involve intermediate costs. They are less expensive than lab studies, but require specific protocols and hence cannot rely on pre-existing data.

As a general approximate rule, field studies carried out at increasing levels of organization will be associated with (i) reduced costs, (ii) complex data analyses owing to more confounding factors, and (iii) poorer access to the underlying mechanisms. When pessimists might conclude that there is no ideal study level, we prefer to view cooperation between studies at different levels as an opportunity to improve the efficiency of studies on parasite interactions. Because they are less costly, upper levels can be used to identify pairs of parasites that are likely to interact and to motivate studies at lower (mechanistic) levels.

Collaborations between several teams and disciplines (e.g., microbiologists, virologists, disease ecologists, community ecologists, social scientists) will facilitate multi-scale studies and improve our understanding of the complex systems that disease ecology necessarily 
deals with. Studies of parasite-parasite interactions in wild population are still at their infancy, and the collection of more empirical data within and across scales, together with methodological and conceptual work, will offer exciting avenues of research. Next-generation epidemiological models will need to be cross-scales, connecting within-host dynamics and between-host dynamics. This is particularly difficult when the link between infection intensity and transmission is unclear and not readily simplified [58]. Consequently, continued observation and experiments on the effects of parasite co-circulation and interactions on parasite and host communities are crucial to allow generalities to emerge and to feed appropriate modeling approaches.

\section{Concluding Remarks}

Inter-specific parasite interactions are one of the biggest challenges of our time for human, plant, and animal health, as well as for conservation and evolutionary biology. Identifying them, deciphering their mechanisms, and understanding their implications will require the interaction of multiple disciplines and diverse study designs, from experiments to long-term longitudinal studies (see Outstanding Questions).

While a better understanding of parasite-parasite interactions offers new management perspectives, more experimental work will be necessary to decipher their underlying mechanisms, and more theoretical work is vital to make predictions about the potential ecological and evolutionary outcomes of control measures [59-61]. Studies should include further reporting and deciphering of interaction mechanisms and consequences (e.g., [62]) in model study systems as well as the development of a predictive theory of multi-parasite epidemics, integrating the different levels of organization and the various highlighted mechanisms $[63,64]$. Biogeographical studies will help to discern potential interactions between parasite species manifesting at large spatial scales by identifying the underlying processes (geographic, abiotic, biotic) that are responsible for the spatial distribution of co-occurring parasite species, and also explain their similar or dissimilar hot-spots of infection [65]. New tools such as next-generation sequencing (NGS) and network analyses will help to better interpret the complex epidemiological patterns observed at each organizational level. Contact or proximity networks of host individuals or species, obtained by bio-loggers or behavioral observations, can be used to estimate the potential transmission pathways of parasites that depend on host behavior [66] and compare them to pathways that were indeed used, as revealed by parasite phylogenies (using sequenced strains of parasites that evolve sufficiently rapidly to be able to track transmission between host individuals [67]). This will permit estimates of whether the observed networks can explain the circulation of each parasite separately, or if their circulation is better explained by interactions between parasites.

Finally, we might benefit from renewing our view of host-parasite interactions. Parasites might be seen as key elements of all ecosystems, including 'internal' ecosystems within host organisms and as evolutionary partners, rather than as enemies that it is necessary to eradicate at all cost (e. g., [68]). Deciphering interactions between parasites and hosts, and taking advantage of them, might be a better approach.

Approaching the problem of parasite-parasite interaction through an ecological perspective may seem to introduce huge complexity into the analysis. However, in this review we hope we have emphasized the benefit of such an approach. First, ecology is 'real life', and mechanisms observed in the lab do not systematically transpose into natural conditions. Second, the wide range of ecological scales at which parasite-parasite interactions can be studied offers important opportunities for a more holistic view, and will help to decide which groups of potentiallyinteracting parasites should be brought to the lab.

\section{Outstanding Questions}

How to identify the mechanisms of parasite-parasite interactions at the host population and community levels? (i) Do parasites manipulate host behavior, thereby modifying the transmission of other parasites? Cotransmission experiments (e.g., with rodents, insects in captivity) may help in this context. (ii) If one parasite alters host dispersion, how does it impact on the spread of other parasites? (iii) Is the circulation of parasites best explained by host contact networks, over-/under-susceptibility of particular individuals, or by parasite interactions?

How best to study the cascade effects of parasite-parasite interactions? (i) How can cascade effects be discerned? Deworming may help to detect parasite interactions and their consequences at different spatial and temporal scales, as can existing broadscale epidemiological data on tracking parasites whose intra-host interaction mechanism is known. (ii) How can contradictory association patterns at different scales be disentangled? Accounting for host demographic parameters by capture-recapture protocols will be crucial; intra-host synergy inducing host surmortality could result in parasites being negatively associated with their host populations. (iii) Do confounding factors or parasite-parasite interactions best explain the parasite association patterns at each scale? The study of confounding factors at less-studied levels, in other words host population and higher levels, as well as multi-scale models are necessary.

Can we predict how parasite-parasite interactions, whose mechanisms occur at low scales (e.g., intra-host), translate to upper levels (e.g., population and regional levels)? (i) Are interactions always visible at higher levels? (ii) Is there a loss of strength in the association between parasites when cascading to upper levels? If so, up to what scale can we detect an interaction occurring at a given scale? (iii)_How do interaction (mechanism, nature) and parasite (transmission mode, life cycle complexity, etc) characteristics influence cascade effects? 


\section{Acknowledgments}

This work was performed within the framework of the LABEX ECOFECT (ANR-11-LABX-0048) at the Universite de Lyon within the program 'Investissements d'Avenir' (ANR-11-IDEX-0007) operated by the French National Research Agency (ANR). We thank Ana Camejo and three anonymous reviewers for helpful comments on this manuscript.

\section{References}

1. Kuris, A.M. et al. (2008) Ecosystem energetic implications of parasite and free-living biomass in three estuaries. Nature 454 , 515-518

2. Rigaud, T. et al. (2010) Parasite and host assemblages: embracing the reality will improve our knowledge of parasite transmission and virulence. Proc. Biol. Sci. 277, 3693-3702

3. Gilbert, C. et al. (2010) A role for host-parasite interactions in the horizontal transfer of transposons across phyla. Nature 464 , $1347-1350$

4. Fumagalli, M. et al. (2011) Signatures of environmental genetic adaptation pinpoint pathogens as the main selective pressure through human evolution. PLoS Genet. 7, e1002355

5. Teixeira, M.G. et al. (2002) Dynamics of dengue virus circulation: a silent epidemic in a complex urban area. Trop. Med. Int. Health 7 , 757-762

6. Bonsall, M.B. (2010) The impact of non-lethal synergists on the population and evolutionary dynamics of host-pathogen interactions. J. Theor. Biol. 262, 567-575

7. Mideo, N. (2009) Parasite adaptations to within-host competition. Trends Parasitol. 25, 261-268

8. Van Geertruyden, J-P. (2014) Interactions between malaria and human immunodeficiency virus anno 2014. Clin. Microbiol. Infect. 20, 278-285

9. Rynkiewicz, E.C. et al. (2015) An ecosystem approach to understanding and managing within-host parasite community dynamics. Trends Parasitol. 31, 1-10

10. Lambin, E.F. et al. (2010) Pathogenic landscapes: interactions between land, people, disease vectors, and their animal hosts. Int. J. Health Geogr. 9, 54

11. Pedersen, A.B. and Fenton, A. (2007) Emphasizing the ecology in parasite community ecology. Trends Ecol. Evol. 22, 133-139

12. Alizon, S. et al. (2013) Multiple infections and the evolution of virulence. Ecol. Lett. 16, 556-567

13. Lello, J. et al. (2004) Competition and mutualism among the gut helminths of a mammalian host. Nature $428,840-844$

14. Johnson, P.T.J. et al. (2013) Host and parasite diversity jointly control disease risk in complex communities. Proc. Natl. Acad. Sci. U.S.A. 110, 16916-16921

15. Telfer, S. et al. (2010) Species interactions in a parasite community drive infection risk in a wildlife population. Science 330, 243-246

16. Blackwell, A.D. et al. (2013) Antagonism between two intestinal parasites in humans: the importance of co-infection for infection risk and recovery dynamics. Proc. Biol. Sci. 280, 20131671

17. Short, F.L. et al. (2014) Polybacterial human disease: the ills of social networking. Trends Microbiol. 22, 508-516

18. Nazzi, F. et al. (2012) Synergistic parasite-pathogen interactions mediated by host immunity can drive the collapse of honeybee colonies. PLoS Pathog. 8, e1002735

19. Taylor, L.H. et al. (2001) Risk factors for human disease emergence. Philos. Trans. R. Soc. Lond. B: Biol. Sci. 356, 983-989

20. Cleaveland, S. et al. (2001) Diseases of humans and their domestic mammals: pathogen characteristics, host range and the risk of emergence. Philos. Trans. R. Soc. Lond. B: Biol. Sci. 356, 991-999

21. Daszak, P. et al. (2000) Emerging infectious diseases of wildlife threats to biodiversity and human health. Science 287, 443-449

22. Pedersen, A.B. and Antonovics, J. (2013) Anthelmintic treatment alters the parasite community in a wild mouse host. Biol. Lett. 9, 20130205

23. Xiridou, M. et al. (2009) How hepatitis D virus can hinder the control of hepatitis B virus. PLOS ONE 4, e5247

24. Harris, R.N. et al. (2009) Skin microbes on frogs prevent morbidity and mortality caused by a lethal skin fungus. ISME J. 3, 818-824
25. Costa, S.R. et al. (2012) Interactions between nematodes and their microbial enemies in coastal sand dunes. Oecologia 170, 1053-1066

26. Rohani, P. et al. (2003) Ecological interference between fata diseases. Nature 422, 885-888

27. Fouchet, D. et al. (2012) Natural simian immunodeficiency virus transmission in mandrills: a family affair? Proc. Biol. Sci. 279, 3426-3435

28. Graham, A.L. (2008) Ecological rules governing helminth-microparasite coinfection. Proc. Natl. Acad. Sci. U.S.A. 105, 566-570

29. Fenton, A. et al. (2010) Detecting interspecific macroparasite interactions from ecological data: patterns and process. Ecol. Lett. 13, 606-615

30. Hellard, E. et al. (2012) True versus false parasite interactions: a robust method to take risk factors into account and its application to feline viruses. PLOS ONE 7, e29618

31. Christensen, N.O. et al. (1987) Heterologous antagonistic and synergistic interactions between helminths and between helminths and protozoans in concurrent experimental infection of mammalian hosts. Parasitol. Res. 73, 387-410

32. Bush, A.O. and Holmes, J.C. (1986) Intestinal helminths of lesser scaup ducks - an interactive community. Can. J. Zool. 64, 142-152

33. Friggens, M.M. and Brown, J.H. (2005) Niche partitioning in the cestode communities of two elasmobranchs. Oikos 108, 76-84

34. Sousa, W.P. (1993) Interspecific antagonism and species coexistence in a diverse guild of larval trematode parasites. Ecol. Monogr. 63, 103-128

35. Stancampiano, L. et al. (2010) Spatial niche competition among helminth parasites in horse's large intestine. Vet. Parasitol. 170 $88-95$

36. Frontera, E. et al. (2005) Evidence of interaction between Ascaris suum and Metastrongylus apri in experimentally infected pigs. Vet. Parasitol. 127, 295-301

37. Lagrue, C. and Poulin, R. (2008) Intra- and interspecific competition among helminth parasites: effects on Coitocaecum parvum life history strategy, size and fecundity. Int. J. Parasitol. 38, 1435-1444

38. Haukisalmi, V. and Henttonen, H. (1993) Coexistence in helminths of the bank vole Clethrionomys glareolus. II. Intestinal distribution and interspecific interactions. J. Anim. Ecol. 62, 230-238

39. Poulin, R. (2001) Interactions between species and the structure of helminth communities. Parasitology 122, S3-S11

40. Behnke, J.M. et al. (2005) Do the helminth parasites of wood mice interact? J. Anim. Ecol. 74, 982-993

41. Jolles, A.E. et al. (2008) Interactions between macroparasites and microparasites drive infection patterns in free-ranging African buffalo. Ecology 89, 2239-2250

42. Lass, S. et al. (2013) Generating super-shedders: co-infection increases bacterial load and egg production of a gastrointestina helminth. J. R. Soc. Interface 10, 20120588

43. Baer, G.M. (1975) In The Natural History of Rabies (Vol. 1), Academic Press

44. Mutze, G. et al. (2002) Emerging epidemiological patterns in rabbit haemorrhagic disease, its interaction with myxomatosis, and their effects on rabbit populations in South Australia. Wildl. Res. 29, $577-590$

45. Cézilly, F. et al. (2014) Cooperation and conflict in host manipulation: interactions among macro-parasites and micro-organisms. Front. Microbiol. 5, 248

46. Poulin, R. et al. (2003) Host sharing and host manipulation by larva helminths in shore crabs: cooperation or conflict? Int. J. Parasitol. $33,425-433$

47. Vickery, W.L. and Poulin, R. (2002) Can helminth community patterns be amplified when transferred by predation from intermediate to definitive hosts? J. Parasitol. 88, 650-656 
48. Lello, J. et al. (2008) Pathogen interactions, population cycles, and phase shifts. Am. Nat. 171, 176-182

49. Abu-Raddad, L.J. et al. (2006) Dual infection with HIV and malaria fuels the spread of both diseases in sub-Saharan Africa. Science 314, 1603-1606

50. Pontier, D. et al. (2009) Emergence of infectious diseases: when hidden pathogens break out. C. R. Biol. 332, 539-547

51. Ezenwa, V.O. and Jolles, A.E. (2015) Opposite effects of anthelmintic treatment on microbial infection at individual versus population scales. Science 347, 175-177

52. Salvador, A.R. et al. (2011) Concomitant influence of helminth infection and landscape on the distribution of Puumala hantavirus in its reservoir, Myodes glareolus. BMC Microbiol. $11,11-30$

53. Munson, L. et al. (2008) Climate extremes promote fatal co-infections during canine distemper epidemics in African lions. PLOS ONE 3, e2545

54. Shrestha, S. et al. (2011) Statistical inference for multi-pathogen systems. PLoS Comput. Biol. 7, e1002135

55. Shrestha, S. et al. (2013) Identifying the interaction between influenza and pneumococcal pneumonia using incidence data. Sci. Transl. Med. 5, 191ra84

56. Grace, J.B. (2006) Structural Equation Modeling and Natural Systems, Cambridge University Press

57. Cumming, G.S. and Guégan, J.F. (2006) Food webs and disease: Is pathogen diversity limited by vector diversity? Ecohealth 3 , $163-170$

58. Cattadori, I.M. et al. (2014) Infections do not predict shedding in co-infections with two helminths from a natural system. Ecology 95, 1684-1692

59. Lozupone, C.A. et al. (2012) Diversity, stability and resilience of the human gut microbiota. Nature 489, 220-230

60. Bull, J.J. and Turelli, M. (2013) Wolbachia versus dengue: evolutionary forecasts. Evol. Med. Public Health 2013, 197-201

61. Vavre, F. and Charlat, S. (2012) Making (good) use of Wolbachia: what the models say. Curr. Opin. Microbiol. 15, 263-268

62. DaPalma, T. et al. (2010) A systematic approach to virus-virus interactions. Virus Res. 149, 1-9

63. Vasco, D.A. et al. (2007) Tracking the dynamics of pathogen interactions: Modeling ecological and immune-mediated processes in a two-pathogen single-host system. J. Theor. Biol. 245, 9-25

64. Fenton, A. (2013) Dances with worms: the ecological and evolutionary impacts of deworming on coinfecting pathogens. Parasitology 140, 1119-1132

65. Blasco-Costa, I. et al. (2015) Biogeography of parasitism in freshwater fish: spatial patterns in hot spots of infection. Ecography 38 , 301-310
66. Godfrey, S.S. (2013) Networks and the ecology of parasite transmission: a framework for wildlife parasitology. Int. J. Parasitol. Parasites Wildl. 2, 235-245

67. Alizon, S.F. et al. (2011) Epidemiological and clinical consequences of within-host evolution. Trends Microbiol. 19, 24-32

68. Vannier-Santos, M.A. and Lenzi, H.L. (2011) Parasites or cohabitants: cruel omnipresent usurpers or creative 'eminences grises'? J. Parasitol. Res. 2011, 214174

69. Van de Perre, P. et al. (2008) Herpes simplex virus and HIV-1: deciphering viral synergy. Lancet Infect. Dis. 8, 490-497

70. Bandilla, M. et al. (2006) A link between ectoparasite infection and susceptibility to bacterial disease in rainbow trout. Int. J. Parasitol. 36, 987-991

71. Massey, R.C. et al. (2004) Interference competition and parasite virulence. Proc. Biol. Sci. 271, 785-788

72. Bashey, F. et al. (2013) Alternative paths to success in a parasite community: within-host competition can favor higher virulence or direct interference. Evolution 67, 900-907

73. West, S.A. and Buckling, A. (2003) Cooperation, virulence and siderophore production in bacterial parasites. Proc. Biol. Sci. 270 $37-44$

74. Ruiz Daniels, R. et al. (2012) Do parasites adopt different strategies in different intermediate hosts? Host size, not host species, influences Coitocaecum parvum (Trematoda) life history strategy, size and egg production. Parasitology 140, 275-283

75. Val, M.E. et al. (2005) The single-stranded genome of phage CTX is the form used for integration into the genome of Vibrio cholerae. Mol. Cell 19, 559-566

76. Biancotto, A. et al. (2008) Upregulation of human cytomegalovirus by HIV type 1 in human lymphoid tissue ex vivo. AIDS Res. Hum. Retroviruses 24, 453-462

77. Nacher, M. et al. (2002) Intestinal helminth infections are associated with increased incidence of Plasmodium falciparum malaria in Thailand. J. Parasitol. 88, 55-58

78. Lusso, P. et al. (1991) Induction of CD4 and susceptibility to HIV1 infection in human $\mathrm{CD} 8^{+} \mathrm{T}$ lymphocytes by human herpesvirus 6 . Nature 349, 533-535

79. Lafferty, K.D. et al. (1994) Analysis of larval trematode communities. Ecology 75, 2275-2285

80. Howard S.C. et al (2001) Methods for estimation of association between multiple species parasite infections. Parasitology 122 233-251

81. Talaat, R.M. et al. (2013) Impact of Schistosoma mansoni and Echinococcus granulosus experimental coinfection on interleukin 10 and interferon gamma cytokines profile. Exp. Parasitol. 134 474-481

82. Fernandez-Nino, J.A. et al. (2012) Paradoxical associations between soil-transmitted helminths and Plasmodium falciparum infection. Trans. R. Soc. Trop. Med. Hyg. 106, 701-708 